\title{
Housing System, Milk Production, and Zero-Grazing Effects on Lameness and Leg Injury in Dairy Cows
}

\author{
M. J. Haskell, ${ }^{1}$ L. J. Rennie, ${ }^{2}$ V. A. Bowell, ${ }^{3}$ M. J. Bell, and A. B. Lawrence \\ Sustainable Livestock Systems Group, Scottish Agricultural College, United Kingdom
}

\section{ABSTRACT}

The aim of this study was to assess the effect of grazing $(G)$ vs. zero-grazing $(\mathrm{ZG})$, level of milk production, and quality and type of housing system [free stalls (FS) and straw yards (SY)] on the prevalence of lameness and leg injuries in dairy cows. Observations were made on 37 commercial dairy farms across Great Britain. A single visit of $5 \mathrm{~d}$ duration was made to each farm. During this visit, lameness scores and the incidence of swellings, rubs, and injuries to hocks and knees were recorded on all the peak- or mid-lactation cows. Aspects of the quality of housing and management that were likely to affect foot and leg health were recorded. There were more lame cows on ZG farms $(39 \pm 0.02 \%)$ than on grazing $(\mathrm{G})$ farms $(15 \pm 0.01 \%)$, and lameness scores were higher on FS farms compared with SY farms $(0.25$ \pm 0.01 vs. $0.05 \pm 0.01$ ). Cows on SY farms had fewer hock and knee injuries compared with FS farms. The frequency of knee swellings was higher on ZG farms $(0.31 \pm 0.02)$ than on $\mathrm{G}$ farms $(0.15 \pm 0.01)$. Aspects of the free-stall design affected foot and leg health. The number of hock swellings increased with increasing stall gradient $(0.16 \pm 0.01$ with no slope vs. $0.39 \pm 0.02$ at a 0 to $1.5 \%$ slope). There was an interaction between the length of the free-stall lunging space and the hip width of the cow, indicating that the incidence of lameness is generally highest on farms with small free stalls and heavy cows. High levels of milk production did not affect lameness or leg injury. The results indicate that housing cows throughout the year potentially has a detrimental effect on foot and leg health. However, good free-stall design may reduce lameness and leg lesions. Key words: lameness, hock injury, management, housing

Received November 25, 2005.

Accepted April 13, 2006.

${ }^{1}$ Corresponding author: marie.haskell@sac.ac.uk

${ }^{2}$ Present address: Faculty of Veterinary Medicine, University of Glasgow, G61 1QH, Scotland.

${ }^{3}$ Present address: Department of Psychology, University of Stirling, FK9 4LA, Scotland.

\section{INTRODUCTION}

Housing systems for dairy cows vary from housing cows throughout the year to housing cows in the winter months only. Cows are allowed outdoors to graze throughout the year in regions with the appropriate climate. Systems in which cows are housed throughout the year [referred to as "zero-grazing" (ZG) systems] are used in areas where grazing the cattle is not the most efficient or cost-effective use of the land. Zerograzing has been practiced in parts of North America since the 1960s (Albright and Alliston, 1971). In Great Britain, this management practice is increasing, whereas the traditional system has cows grazing at pasture for the summer months. Cows can be fed high levels of concentrate feed more easily when they are housed, so extended or continuous housing systems are more common on farms having cows with a high genetic potential for milk yield. It is hypothesized that the increased length of the housing period may have adverse effects on cow lameness and leg injury. Lameness is not only a significant and painful welfare problem for the cow (Logue and Offer, 2001), but milk production is adversely affected, causing significant economic losses for farmers (Kossaibati and Esslemont, 1997; Green et al., 2002). Lameness in dairy cattle is widespread, with studies showing up to $50 \%$ of the cattle affected on some farms (Whay et al., 2003).

A number of studies have examined the effect of different types of housing and management system on lameness. Lameness and hoof damage have been shown to be lower in straw-yard (SY) farms than in free-stall (FS) or cubicle housing (Logue and Offer, 2001; Somers et al., 2003), although some types of foot lesions are more frequent in SY farms (Livesey et al., 1998). Housing cows on concrete is thought to adversely affect the health of the legs and feet because of its unyielding nature. Using a softer layer of rubber on the concrete surface of the alleyways or as flooring appears to reduce leg and claw lesions compared with concrete or wood flooring alone (Vokey et al., 2001). However, the use of cushioning surfaces, such as mats or mattresses, within the FS does not appear to reduce lameness (Chaplin et al., 2000b). Injury to the hocks and knees of the cow appears to be caused by abrasion on concrete surfaces 
or by collision with stall partitions when cows lie down and stand up. In most cases, sand, sawdust, or straw bedding in stalls causes less damage to joints than do mats (Weary and Taszkun, 2000; Wechsler et al., 2000; Vokey et al., 2001).

The aim of this study was to test the hypothesis that extended periods of housing affect the prevalence of lameness and hock and knee injuries in dairy cattle on commercial dairy farms. In addition, the type of housing (SY vs. FS), level of milk production, quality of housing (such as the stall dimensions and the presence of stall bedding), and the quality of stock handling on foot and leg health were examined. The quality of stock handling was included because the quality of interactions between the stockpersons and the animals has been shown to affect the productivity and welfare of the cattle (Hemsworth et al., 2000).

\section{MATERIALS AND METHODS}

\section{Farms}

The study was performed with dairy cows on commercial dairy farms. Because the study could include only a relatively small number of farms, a classification system was needed that would allow us to select farms for the study that represented the major types of dairy farms in Great Britain. Three hundred questionnaires, which contained 28 questions on the farm, the cows, and the management system, were sent out to farmers randomly selected from advisory clients of the Scottish Agricultural College and to members of the Holstein breed society (Holstein-UK, Rickmansworth, Herts, UK). A principal components analysis (PCA) was used to analyze data from the 111 questionnaires returned. This analysis examines the relationships among variables and determines whether they can be represented by a smaller number of variables, called principal components (Jobson, 1992). An initial analysis indicated that a number of the variables were related and that a number showed very little variation. In the final PCA analysis, the noninformative variables were excluded, whereas the major variables that represented the clusters in the initial PCA were retained. The variables selected for the final PCA analysis were number of cows in the herd, average genetic merit of the herd for milk production, average milk yield, amount of concentrate fed per cow, type of forage fed, housing type and size of the groups within the herd, and total number of cows on the farm. The first 2 principal components explained 30.1 and $21.5 \%$ of the variation in the data, respectively. The first principal component was milk production, with the farms classified as high, medium, or low production. The second principal component described housing type, with SY farms distinguished from FS farms. However, the SY farms were mostly classified as medium milk production on principal component 1 . Therefore, 4 farm types represented the range: high production (HP: $\geq 9,000 \mathrm{~L} / \mathrm{yr} ; \mathrm{n}=7$ ) with FS housing; medium production (MP: 7,300 to $8,900 \mathrm{~L} / \mathrm{yr} ; \mathrm{n}=8$ ) with FS housing (MP-FS); medium production with SY (MP-SY, $\mathrm{n}=7$ ); and low production with FS housing (LP: $<7,300 \mathrm{~L} / \mathrm{yr} ; \mathrm{n}=7$ ). In the questionnaire, $\mathrm{ZG}$ farms tended to have high levels of milk production compared with grazing $(\mathbf{G})$ farms, and most used FS housing. Because these farms were of special interest in this study, HP-ZG farms with FS housing were included as a fifth group in the study $(\mathrm{n}=8)$. In addition to these criteria, to standardize for breed and number of cows, only farms with 90 or more Holstein or HolsteinFriesian cows were used. However, in the statistical analysis the major factors (management system, housing system, and milk production) were assessed separately (see below).

\section{Farm Visits and Cows}

Thirty-seven dairy farms across Great Britain were visited. Each farm was visited once during the winter months when the cows were housed, and the visits were completed over 3 winters (November 2000 to April 2003). The first farm visits of the winter season were made at least $3 \mathrm{wk}$ after the cows were brought indoors to allow them to become accustomed to housing. Farm visits continued into the early spring before the cows were turned out. As far as possible, the 5 farm types were visited in turn to balance the effect of farm type with the effect of increased time spent housed. Five consecutive days were spent on each farm taking a number of measures of health and behavior. Wherever possible, the observations were focused on the group of cows in the first or second third of lactation on each farm (up to approximately $200 \mathrm{DIM}$ ), because previous research has shown that health and welfare issues are most frequent in this period (Chaplin et al., 2000a).

\section{Measurements}

Three experimenters were trained in and involved with taking the measurements. The methods were practiced and individual scores were verbally compared among the experimenters.

Lameness. Cows were scored individually as they entered and exited the milking parlor. The observer stood in the parlor pit, with the lower part of the legs of the cows at the observer's eye level. The authors acknowledge that the best way to assess lameness is to observe each cow walking for some distance on a flat, even surface. However, the layout of yards on some of 
Table 1. Description of the lameness scoring system

\begin{tabular}{ll}
\hline Locomotion score & Description \\
\hline 1-Sound & Little or no limb adduction or abduction. Even gait. No signs of leg or foot soreness \\
or lameness. Cow walks willingly and hind feet move to the spot vacated by fore feet in the walk. \\
2-Slightly uneven gait \\
Some limb adduction or abduction. May have slight unevenness of gait. Cow moves willingly, \\
but hind feet may not be placed in the spot vacated by fore feet. \\
G-Lame \\
slight abnormality evident. Lameness can be due either to a major problem with one limb or to \\
of lameness when stationary (e.g., change in posture). May be reluctant \\
to move and is tentative with the sore limb. \\
Can be identified as lame from a distance. One or more limbs may be affected. Cow nods on walking. \\
Cow hobbles, is reluctant to move. Gait is stilted, very tentative with affected limb(s). \\
Cow has difficulty in turning. \\
Extremely lame. Cow is possibly recumbent or reluctant to stand. Very unwilling or unable to move. \\
May have limb tucked up against the body. \\
\hline
\end{tabular}

the farms did not allow observation for an extended period outside the milking parlor. Observation of the cows from within the parlor pit allowed lameness scoring to be standardized across farms. The cows were scored on a 1 to 5 scale using a modified version of the system of Manson and Leaver (1988; Table 1), in which a score of 1 equates with an animal that is sound in gait and 5 is given to an animal that is very lame and reluctant to rise or move. The freeze brand numbers of the cows were used for identification.

Hock and Knee Injuries. During a second milking, the presence or absence of injuries to the hocks and knees was scored. The presence of swellings (filling or enlargement of the joint), scratches (exposed or broken skin), and rubs (callused areas), and the number of joints affected $(0,1$, or 2$)$ were recorded for both hocks and knees. Each cow therefore had 6 injury scores, each with a range of 0 to 2 .

Hip Width and Speed of Movement. The distance between the hip bones was measured using a metal measuring tape to estimate the weight of the cow. Hip width has been shown to be highly correlated with live weight (Heinrichs et al., 1992). The observers scored the speed with which the cows were moved by the handler toward the milking parlor on each of $2 \mathrm{~d}$. Speed was scored using a system in which the observer subjectively rated the speed on a sliding scale from 1 (slow) to 10 (fast). The scale was represented by a $10-\mathrm{cm}$ line, and the observer put a stroke across the line at the point between "slow" and "fast" that best represented the speed (Wemelsfelder et al., 2001). This measure was shown to correlate highly with other measures of stockmanship, such as the number of positive and negative actions used to move the cows (Rennie, 2004).

Building Quality and Management Variables. A number of measures were made on housing variables that can contribute to health and welfare. These included recording the number of cows in the group, the size of the pen for that group, the ratio of cows to stalls or area of SY per cow, and the length of feed-bunk space available per cow. For farms with FS, the presence of mats or mattresses in the stalls and whether any type of bedding was added on top of the mats or mattresses (sawdust, straw, etc.) was recorded. The length, width, slope, step, or curb height, and the length of the lunging space in the stalls were measured using a tape measure and spirit level. The length of the stall bed was taken as the distance from the rear curb to the supporting posts, wall, or boarding at the front of the stall, and the width was the distance between the stall partitions. The lunging space is the part at the front of the stall, separated from the lying area, that allows the cow to move her weight forward when moving from lying to standing. The length of the lunging space was measured as the distance from the brisket board or rail to the front of the stall. The gradient or slope of the stall was calculated from the difference between the heights of the curbs at the front and rear of the stalls, or by measuring the drop along a known length.

\section{Statistical Analysis}

The data were analyzed using Genstat Version 7.2 (2004; Lawes Agricultural Trust, Rothamsted Experimental Research Station, Harpenden, Hertfordshire, UK). The relationship between total number of leg injuries and lameness score was investigated by calculating a product-moment correlation coefficient and testing the relationship using linear regression. The effect of the explanatory variables [management system $(\mathrm{G}$ vs. ZG), housing system (SY vs. FS), and level of milk production (LP vs. MP vs. HP)], housing quality, cow hip width, and speed of movement on lameness and hock and knee injuries was investigated. Further, the effect of variables relevant only to FS farms (stall length, stall width, etc.) was investigated in a second series of analyses, which excluded the SY farms. The data were analyzed using a generalized linear mixed 
model by the method of Breslow and Clayton (1993). Observer identity and the interaction between farm identity and observer were fitted as random effects to control for the effects of the individual farm and the variation among observers in their scoring of lameness and leg injury. A binomial error distribution was assumed and a logistic link function was used. Wald tests, which use a $\chi^{2}$ distribution, were used to examine the level of significance of the differences.

The distribution of lameness scores was nonnormal, so the 1 to 5 range of scores was converted to a binary trait $(0,1)$ in which scores 1 and 2 became "sound" and were given a score of 0 , and scores 3 to 5 became "lame" and were given a score of 1 . To prevent outlying values from exerting exaggerated effects or leverage on the analysis, the continuous variables (e.g., stall length, stall width, etc.) were separated into 4 classes using the interquartile ranges of each variable. Examination of the distribution of the gradients of the FS indicated that it fell more logically into 3 categories than $4(0$ gradient, between 0 and $1.5 \%$, and greater than $1.5 \%$ ). When a large number of explanatory variables exist, the traditional approach to statistical model building has been to minimize the number of variables to ensure that the resultant model is numerically stable (Hosmer and Lemeshow, 2000). To reduce the number of variables included in the final modeling, all variables were screened. This involved analyzing the effect of each variable on its own (a univariate analysis) with each outcome variable (lameness and each of the hock and knee injuries). Any variable that had a $P$-value greater than 0.25 became a candidate for the multivariate model for each outcome trait (Hosmer and Lemeshow, 2000). This subset of variables was then used in a multivariate analysis. Where there appeared to be confounding between the variables in the multivariate model, the interacting effects were examined by rerunning the multivariate model with and without each of the variables in question and examining the effect on the remaining variables. Where previous research had suggested a significant effect of one of the confounding variables, this variable was retained and the other removed. Because the relative importance of the variables investigated is not completely known, the significance of each term was taken as the value as if it were fitted after all other variables had been fitted-that is, at the end of the list of variables in the multivariate analysis, which is the most conservative approach. Raw data means and standard errors of the means are presented in the results. Tests with $P$-values with a significance of less than 0.05 are considered to be significant.

\section{RESULTS}

\section{General Distribution of Lameness and Leg Injuries}

On the 37 farms, 2,724 cows were scored. The lameness scores ranged from 1 (sound) to 5 (very lame), with
Table 2. Mean number of injuries per cow ${ }^{1}$

\begin{tabular}{ll}
\hline Type of injury & Mean (SEM) \\
\hline Hock scratches & $0.44(0.01)$ \\
Hock rubs & $0.99(0.02)$ \\
Hock swellings & $0.23(0.01)$ \\
Knee scratches & $0.05(0.01)$ \\
Knee rubs & $0.11(0.01)$ \\
Knee swellings & $0.22(0.01)$ \\
\hline
\end{tabular}

${ }^{1}$ Scale: from 0 to 2 limbs affected.

a median of 2 . The most common injuries were hock rubs, with almost all cows having at least one limb affected (Table 2). The least common injuries were knee rubs and knee scratches. There was a correlation between the lameness score and the total number of injuries on the legs of cows $(\mathrm{r}=0.46 ; t=25.81, P<0.001)$.

\section{Effect of Housing and Management on Lameness and Leg Injuries}

Effect of Housing System. Cows on SY farms had lower lameness scores $(P<0.05$; Table 3$)$ and fewer hocks rubs $(P<0.001)$, hock scratches $(P<0.05)$, hock swellings $(P<0.05)$, and knee swellings $(P<0.05)$ than did cows on FS farms.

Effect of $\boldsymbol{Z} \boldsymbol{G}$ vs. G. Zero-grazing farms had higher levels of lameness and knee swellings when only FS farms were considered (Table 4). The factors FS vs. SY, ZG vs. G, speed of cow movement, and length of feed bunk per cow showed some level of covariance.

Effect of Level of Milk Production. There were very few effects of level of milk production on lameness or injury. Farms with LP had higher levels of knee swellings compared with farms with higher levels of milk production (Table $3 ; P<0.05$ ).

Effect of Lactation Number. Lameness, hock rubs, and knee swellings all increased with age (lameness: $P<0.001$; hock rubs: $P<0.001$; knee swellings: $P<$ 0.01 ; Table 3). The effect of lactation number on these traits was apparent when the FS farms were considered alone (Table 4).

Effect of Hip Width. Cows with large hip widths had more hock swellings than did cows with smaller hip widths $(P<0.01$; Table 3$)$. When the FS farms were considered alone, there was an interaction between hip width of the cow and length of the lunging space of the FS on the level of lameness $\left(\mathrm{W}_{15}=33.35 ; P<0.01\right.$; Table 5). Generally, the lowest lameness scores were associated with more lunging space, except for cows with $>55 \mathrm{~cm}$ of hip width, which had high scores from $<0.35$ to $0.55 \mathrm{~m}$ of lunging space.

Speed of Movement. Significant relationships among hock swellings, knee swellings, and speed of 
Table 3. Results (means \pm SEM) from the multivariate analyses showing the effect of explanatory variables on lameness and hock and knee injuries on all farms ${ }^{1}$

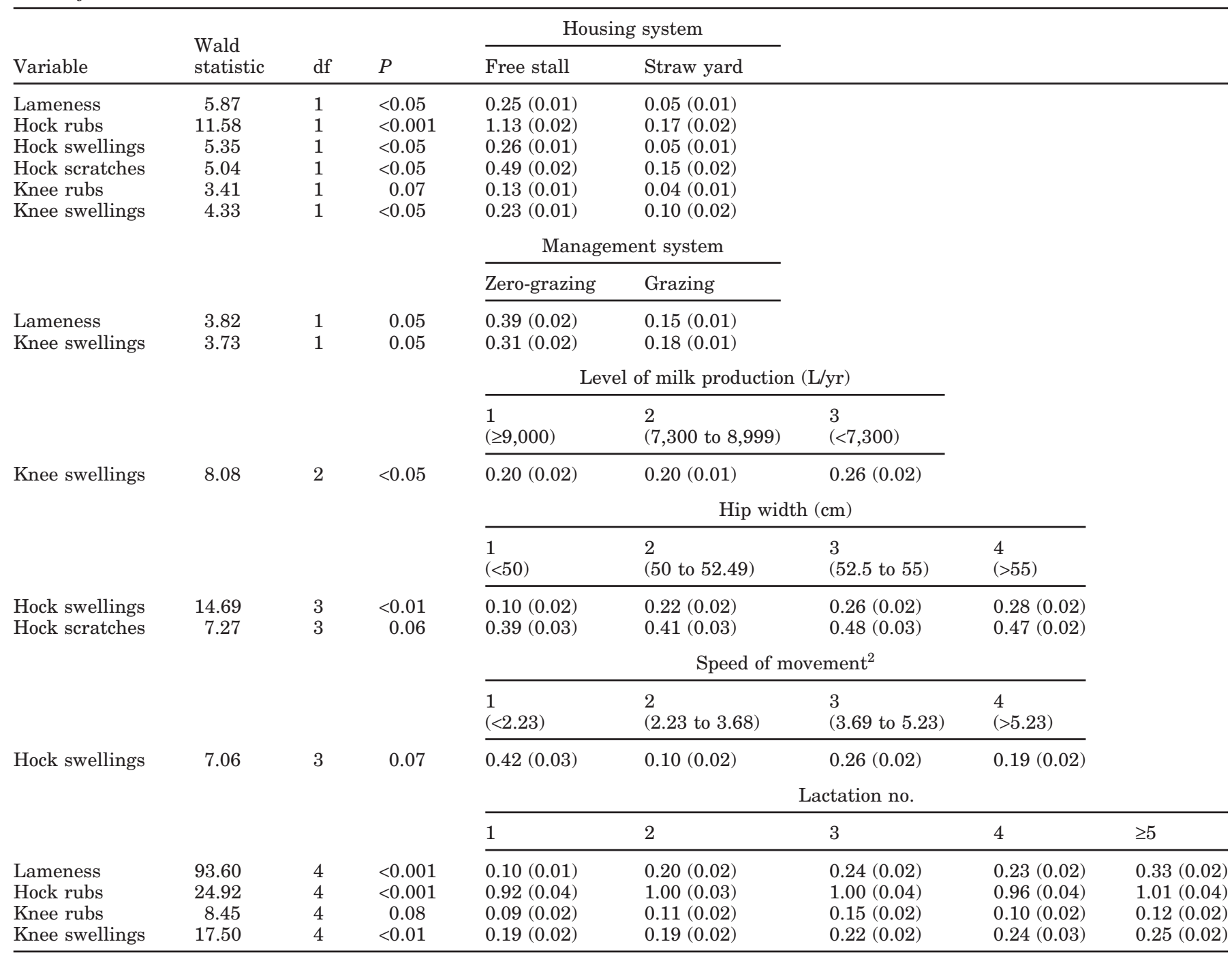

${ }^{1}$ Only variables with statistically significant effects or tendencies are shown. Wald statistics, $P$-values, and means \pm SEM are shown for the categories within that explanatory variable. Lameness scores range from 0 to 1 , where 0 represents a category with no lame cows and 1 represents a category with all lame cows. For hock and knee injuries, 0 represents a category in which all cows have none of that particular injury on either leg, and 2 represents a category in which all cows have the injury on both legs.

${ }^{2}$ Scale of 1 to 10 : 1 = slow; 10 = fast.

movement were shown when the FS farms were analyzed alone, showing that cows with more injuries moved more slowly (Table 4).

FS Design. The effect of lunging space on lameness is shown in Tables 4 and 5. Cows in stalls with the smallest stall lunging space had the highest occurrence of knee swellings $(P<0.05)$. Lameness was affected by the gradient of the stall (Table 4), with lameness scores highest at intermediate gradients and lower in flat stalls and stalls with high gradients $(P<0.05)$. Hock swellings increased with increasing stall gradient $(P$ $<0.05)$.

\section{DISCUSSION}

This study showed that lameness is higher in cows on ZG farms using FS than on G farms. The FS and ZG systems would appear to increase lameness independent of the level of milk production and stall quality (Table 4). Somers et al. (2003) found that cows on ZG farms had higher numbers of claw disorders compared with cows on non-ZG farms. The increase in lameness may be due to the concussive effects of concrete, or to continual exposure of the feet to slurry (Cook et al., 2004), but these effects could not be differentiated in 
Table 4. Results (means \pm SEM) from the multivariate analyses showing the effect of explanatory variables on lameness and hock and knee injuries for farms with free stalls only ${ }^{1}$

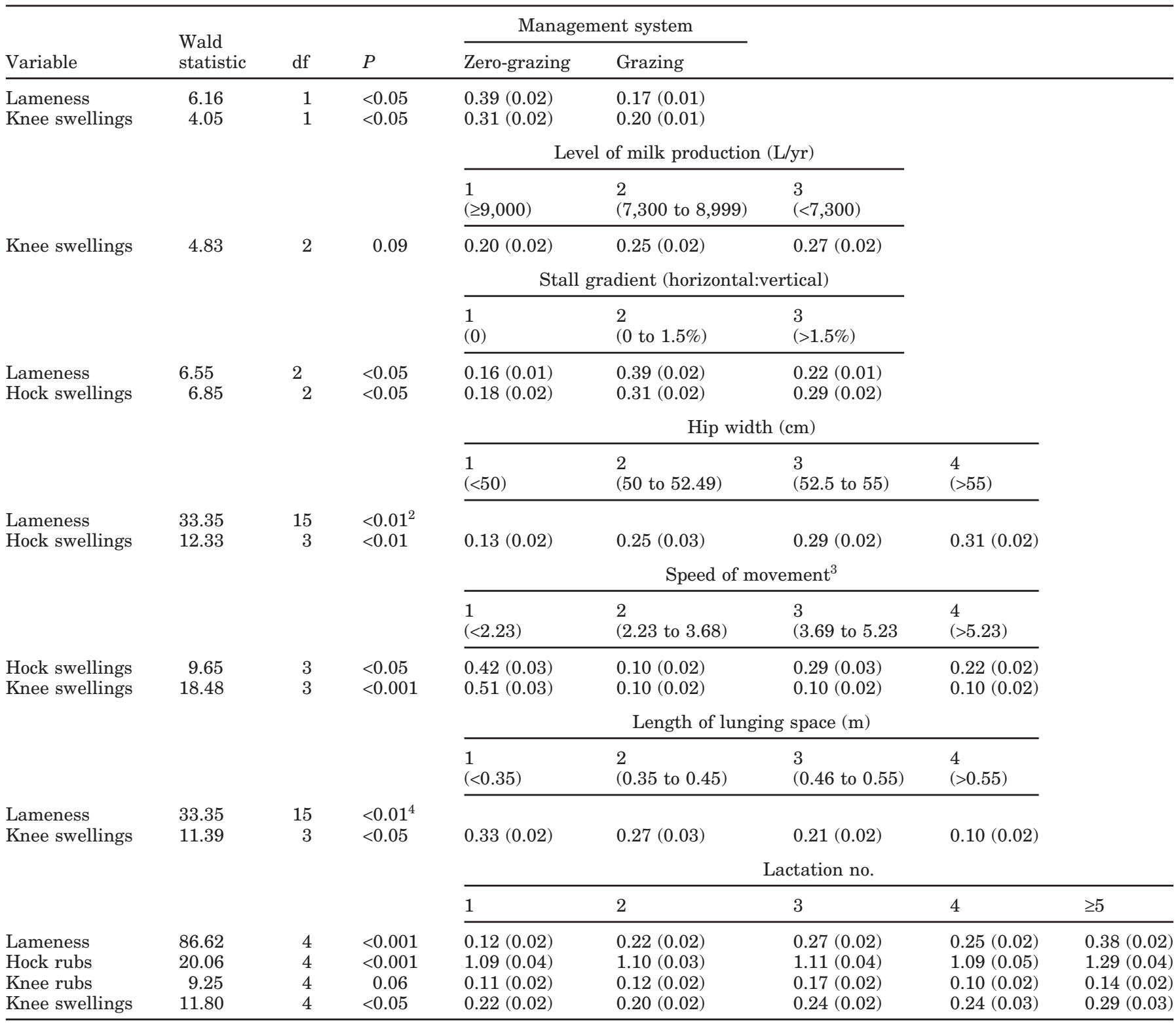

${ }^{1}$ Only variables with statistically significant results are shown. Wald statistics, $P$-values, and means \pm SEM are shown for the categories within that variable. Mean lameness scores range from 0 to 1 , where 0 represents a category with no lame cows and 1 represents a category with all lame cows. For hock and knee injuries, 0 represents a category in which all cows have none of that particular injury on either leg, whereas 2 represents a category in which all cows have the injury on both legs.

${ }^{2}$ Interaction with length of lunging space (see text).

${ }^{3}$ Scale of 1 to $10: 1$ = slow; 10 = fast.

${ }^{4}$ Interaction with hip width (see Table 5).

this study. Zero-grazing farms had higher levels of knee swellings, which were likely a result of pressure on the knees as the cows moved from standing to lying, or vice versa. Similar to other studies, we showed that lameness (Rowlands et al., 1985; Green et al., 2002) and occurrence of leg injury (Weary and Taszkun, 2000) appeared to increase with age, and were lower on SY farms than on FS farms (Logue and Offer, 2001; Livesey et al., 2002; Somers et al., 2003).

The design of FS and their ability to provide comfort for the cow are important aspects of housing for dairy cows. The dimensions of the various parts of the stall (Cermak, 1982) have received attention with regard to cow comfort. The present study suggests that the length 
Table 5. Mean ( \pm SEM) lameness scores for the interaction between length of lunging space and hip width on lameness

\begin{tabular}{|c|c|c|c|c|}
\hline \multirow[b]{2}{*}{$\begin{array}{l}\text { Hip-width } \\
\text { category }(\mathrm{cm})\end{array}$} & \multicolumn{4}{|c|}{ Length of lunging space (m) } \\
\hline & $\begin{array}{c}1 \\
(<0.35)\end{array}$ & $\begin{array}{c}2 \\
(0.35 \text { to } 0.45)\end{array}$ & $\begin{array}{c}3 \\
(0.46 \text { to } 0.55)\end{array}$ & $\begin{array}{c}4 \\
(>0.55)\end{array}$ \\
\hline $1(<50)$ & $0.11(0.04)$ & $0.06(0.03)$ & $0.10(0.05)$ & $0.06(0.02)$ \\
\hline $2(50$ to 52.49$)$ & $0.33(0.04)$ & $0.08(0.02)$ & $0.08(0.03)$ & $0.09(0.02)$ \\
\hline $3(52.5$ to 55$)$ & $0.39(0.03)$ & $0.26(0.04)$ & $0.30(0.04)$ & $0.12(0.04)$ \\
\hline $4(>55)$ & $0.48(0.03)$ & $0.34(0.05)$ & $0.33(0.03)$ & $0.07(0.03)$ \\
\hline
\end{tabular}

of the lunging space (Tables 4 and 5) contributes to the occurrence of knee swellings and to lameness, particularly in cows with larger hip widths. Because hip width is correlated with live weight (Heinrichs et al., 1992), the interaction indicates that heavier cows were more likely to be adversely affected by small lunging spaces. When cows move from lying to standing, they move their weight forward to the forequarters, then raise the hindquarters and finally the forequarters (Cermak, 1982). If the lunging space is too short, moving from lying to standing may be very awkward for the cow, placing strain on her joints. Previous research has suggested a link between the length of the lunging space and leg health (Cermak, 1982; McFarland and Gamroth, 1994), and this study provides some verification. The recommended length for the lunging space is $0.7 \mathrm{~m}$ (Cermak, 1982). Less than one-quarter of the farms in this study had this amount of space available, although this must be related to the size of the cow. By recording lunging space as the distance from the brisket board to the rail or wall at the front of the stall, a conservative measure of lunging space was used, because cows in head-to-head stalls may use the space at the front of the opposite stall when rising. Therefore, some cows will have an actual lunging space larger than recorded. However, the presence of an association between lameness and length of lunging space in this study indicates that the length of the lunging space is a risk factor for lameness, perhaps because sharing of lunging space cannot always be assumed to occur. Cows with greater hip widths appeared to suffer from more hock swellings (Tables 3 and 4) and hock scratches (Table 3). This may be due to cows being housed in stalls that are too small, resulting in the hind legs rubbing on the edge of the stall curb.

This study showed that the gradient of the stall affects foot and leg health. Lameness was highest at intermediate stall gradients ( $>0$ to $1.5 \%$; Table 4 ), whereas levels of hock swellings increased with increasing gradients (from 0 to $>1.5 \%$ ). However, the result may indicate that strain is placed on the legs when rising. Because cows often choose to lie facing slightly uphill when lying at pasture, it would seem unlikely that cows are choos- ing not to lie in sloping stalls because they are uncomfortable. Moreover, in terms of injury, cows slip backward in stalls with slopes of 4 and 7\%, and slip forward in stalls of $-1 \%$ (Nørgaard et al., 2003). If cows slip backward, this could bring their hocks into contact with the edge of the curb, causing abrasion and swelling. Free stalls are designed to be sloped to allow urine to drain to keep the bedding dry and prevent udder infections (McFarland and Gamroth, 1994). However, an optimal stall gradient is needed-one that provides drainage but does not contribute to lameness and hock injury.

Speed of movement was measured as an indicator of the quality of stock handling (Table 4), with a slow speed of movement assumed to reflect a calmer, more patient stock handler. The results suggest that cows with hock and knee swellings are moved more slowly. This may be because cows with these joint injuries are not capable of moving fast and that stock handlers respond to this. Because other studies have shown an effect of stock handler quality on production and stress in farm animals, the effect of stock handler ability on lameness and other health issues merits further attention (Hemsworth et al., 2000).

In conclusion, it would appear that ZG farms face the risk of increased lameness and knee injuries in their cows. However, these farmers could possibly counteract the negative effects of this management system by using treatments such as regular foot trimming and foot bathing, or by giving their cows access to soft standing areas, which are known to improve foot health (Blowey, 1993). Using SY in ZG systems could also be an option. Using FS with the appropriate design may improve foot and leg health. This study has highlighted the effects of the length of the lunging space and the stall gradient on lameness characteristics. Because lameness can cause economic losses for the farmer (Kossaibati and Esslemont, 1997; Green et al., 2002), expenditure on improving FS may be offset by improvements in production.

\section{ACKNOWLEDGMENTS}

Many thanks to Jo Dearing, Tine Rousing, Marianne Farish, Emma Baxter, Julie Stephenson, Joan Chirn- 
side, Graham Hunter, and Kirsty McLean for on-farm help. David Logue and Gary Tierney gave valuable assistance in refining the methods, and Malcolm Hall gave invaluable statistical advice. We would like to thank Holstein-UK, National Milk Records (Chippenham, Wiltshire, UK), and Cattle Information Systems for access to their databases. We are grateful to Defra (Department for the Environment, Food and Rural Affairs, London, UK) for funding this study, and are particularly grateful to the farmers who participated in this study.

\section{REFERENCES}

Albright, J. L., and C. W. Alliston. 1971. Effects of varying the environment upon the performance of dairy cattle. J. Anim. Sci. $32: 566-577$.

Blowey, R. 1993. Cattle Lameness and Hoofcare: An Illustrated Guide. Farming Press, Ipswich, UK.

Breslow, N. E., and D. G. Clayton. 1993. Approximate inference in generalized linear mixed models. J. Am. Stat. Assoc. 88:9-25.

Cermak, J. 1982. Zoocentric approach to definition of cubicle length and width for Friesian dairy cows. Pages 41-48 in Proc. Br. Cattle Vet. Assoc. Proc. for 1981-1982. Beecham Animal Health, Betchworth, UK.

Chaplin, S. J., H. E. Ternent, J. E. Offer, D. N. Logue, and C. H. Knight. 2000a. A comparison of hoof lesions and behaviour in pregnant and early lactation heifers at housing. Vet. J. 159:147-153.

Chaplin, S. J., G. Tierney, C. Stockwell, D. N. Logue, and M. Kelly. $2000 \mathrm{~b}$. An evaluation of mattresses and mats in two dairy units. Appl. Anim. Behav. Sci. 66:263-272.

Cook, N. B., K. V. Nordlund, and G. R. Oetzel. 2004. Environmental influences on claw horn lesions associated with laminitis and subacute ruminal acidosis in dairy cows. J. Dairy Sci. 87(E Suppl.):E36-E46.

Green, L. E., V. J. Hedges, Y. H. Schukken, R. W. Blowey, and A. J. Packington. 2002. The impact of clinical lameness on the milk yield of dairy cows. J. Dairy Sci. 85:2250-2256.

Heinrichs, A. J., G. W. Rogers, and J. B. Cooper. 1992. Predicting body weight and wither height in Holstein heifers using body measurements. J. Dairy Sci. 75:3576-3581.

Hemsworth, P. H., G. J. Coleman, J. L. Barnett, and S. Sorg. 2000 Relationships between human-animal interactions and productivity of commercial dairy cows. J. Anim. Sci. 78:2821-2831.

Hosmer, D. W., and S. Lemeshow. 2000. Applied Logistic Regression. John Wiley \& Sons, Toronto, Canada.
Jobson, J. D. 1992. Applied Multivariate Data Analysis: Categorical and Multivariate Methods. Vol. 2. Springer Verlag, New York.

Kossaibati, M. A., and R. J. Esslemont. 1997. The costs of production diseases in dairy herds in England. Vet. J. 153:41-51.

Livesey, C. T., T. Harrington, A. M. Johnston, S. A. May, and J. A. Metcalf. 1998. The effect of diet and housing on the development of sole haemorrhages, white line haemorrhages and heel erosions in Holstein heifers. Anim. Sci. 67:9-16.

Livesey, C. T., C. Marsh, J. A. Metcalf, and R. A. Laven. 2002. Hock injuries in cattle kept in straw yards or cubicles with rubber mats or mattresses. Vet. Rec. 150:677-679.

Logue, D. N., and J. E. Offer. 2001. The effect of forage type on foot health in dairy heifers. Vet. J. 162:7-8.

Manson, F. J., and J. D. Leaver. 1988. The influence of concentrate amount on locomotion and clinical lameness in dairy cattle. Anim. Prod. 47:185-190.

McFarland, D. F., and M. J. Gamroth. 1994. Freestall designs with cow comfort in mind. Pages 145-158 in Dairy Systems for the 21st Century: Proc. Third Int. Dairy Housing Conf., American Society of Agricultural Engineers, St. Joseph, MI.

Nørgaard, P., N. Rrbech, and P. M. Christensen. 2003. Effect of slope of cubicle floor on lying and ruminating behaviour in cattle tied in experimental box stalls. Pages 282-287 in Proc. Fifth Int. Dairy Housing Conf., American Society of Agricultural Engineers, St. Joseph, MI.

Rennie, L. J. 2004. On-Farm Welfare Assessment of Holstein-Friesian Dairy cows: A Preliminary Investigation into Two Novel Behavioural Measures. MPhil thesis, University of Edinburgh, Edinburgh, UK.

Rowlands, G. J., A. M. Russell, and L. A. Williams. 1985. Effects of stage of lactation, month, age, origin and heart girth on lameness in dairy cattle. Vet. Rec. 117:576-580.

Somers, J. G. C. J., K. Frankena, E. N. Noordhuizen-Stassen, and J. H. M. Metz. 2003. Prevalence of claw disorders in Dutch dairy cows exposed to several floor systems. J. Dairy Sci. 86:2082-2093.

Vokey, F. J., C. L. Guard, H. N. Erb, and D. M. Galton. 2001. Effects of alley and stall surfaces on indices of claw and leg health in dairy cattle housed in a free-stall barn. J. Dairy Sci. 84:2686-2699.

Weary, D. M., and I. Taszkun. 2000. Hock lesions and free-stall design. J. Dairy Sci. 83:697-702.

Wechsler, B., J. Schaub, K. Friedli, and R. Hauser. 2000. Behaviour and leg injuries in dairy cows kept in cubicle systems with straw bedding or soft lying mats. Appl. Anim. Behav. Sci. 69:189-197.

Wemelsfelder, F., E. A. Hunter, M. T. Mendl, and A. B. Lawrence. 2001. Assessing the "whole animal": A free choice profiling approach. Anim. Behav. 62:209-220.

Whay, H. R., D. C. J. Main, L. E. Green, and A. J. F. Webster. 2003. Assessment of the welfare of dairy cattle using animal-based measurements: Direct observations and investigations of farm records. Vet. Rec. 153:197-202. 